\title{
Rhetorical Strategies in Advertising: The Rise and Fall Pattern
}

\author{
Anne A. Christopher \\ School of Education and Modern Languages \\ College of Arts \& Sciences, Universiti Utara Malaysia \\ althea@uum.edu.my
}

\section{Doi:10.5901/ajis.2013.v2n8p773}

\begin{abstract}
Throughout the decades, there have been changes in persuasive strategies used by advertisers. A study was carried out on 500 advertising slogans dating from the late $19^{\text {th }}$ century till the early $21^{\text {st }}$ century, spanning a period of over a hundred years. The slogans were selected from 13 multinational and established companies and arranged according to the year they were created. The companies selected were ones that existed from the late 1800 s and which still exist today. A cross-section of the slogans were analysed qualitatively for the presence of rhetorical figures and various persuasive strategies in a pilot study. The trend of the use of rhetorical figures and communicative and stylistic strategies used throughout this period was also calculated using quantitative analysis. The findings reveal a rise and fall pattern throughout the decades of both rhetorical figures and communicative and stylistic strategies used in advertising slogans. The pattern is also present in the layering of the rhetorical figures throughout the decades. Therefore the study has discovered the presence of a cyclical continuum that involves the selection of certain rhetorical figures and persuasive strategies in a particular period but not in others.
\end{abstract}

Keywords: advertising slogans, rhetorical figures, persuasive strategies, rise and fall pattern

\section{Introduction}

Advertising is pervasive as we are bombarded with persuasive messages from all corners. From radio to television commercials to advertisements on public transport to billboards and the internet, we are constantly persuaded to believe in something or behave in a certain way. If we think of advertising as a way of disseminating information to carry out business, we might say advertising began ages ago. When people bring some of their crops to the market and stand there shouting their wares, they are actually advertising their products. Advertisers have used numerous persuasive strategies throughout the ages.

\section{Rhetorical Figures in Advertising}

A rhetorical figure has been traditionally referred to as an artful deviation from the usual or ordinary mode of expression, whether in speech or writing. It occurs when an expression departs from the norm, is not discarded as being unintelligible or defective, it deviates in form rather than content, and the deviation complies to a fixed pattern according to specific contents and contexts. A figure in the schematic mode or scheme (Greek schema, form, shape) has the feature of excessive order or regularity while a figure in the tropic mode or trope (Greek tropein, to turn) is associated with a lack of order or irregularity. The latter term is used to represent the domain of figurative language. Used skillfully, tropes give language greater force and accuracy which is vital in persuasion. Thus schemes and tropes cover two well-defined modes of formal deviation. Both schemes and tropes entail a shift of some kind: a trope involves a shift of meaning i.e. it operates at the conceptual or semantic level, a scheme involves a shift of order i.e. it operates at the physical or sensory level of the language structure. A trope alters the meanings of words whereas a scheme only affects their positioning or repetition. Common examples of schemes include parallelism and alliteration, and metaphors and puns are examples of tropes (Corbett \& Connors, 1999; Cockcroft and Cockcroft, 2005; McQuarrie and Mick, 1996; Mothersbaugh, Huhmann, \& Franke, 2002).

There are slogans that use only schemes and there are slogans that use only tropes. An example that uses only schemes is PepsiCo Incorporated's 1969 slogan, You've got a lot to live. Pepsi's got a lot to give which contains five schemes, namely, assonance, parison, rhyme, chime and mesodiplosis. An example of a slogan that uses only tropes is the 2005 Guinness slogan, Brilliant! which contains three tropes, namely, ellipsis, metonymy and pun. Only a small percentage of slogans do not use any rhetorical figure at all. Many slogans use just one rhetorical figure but these are 
outnumbered by a larger proportion of slogans that use a layer of figures. Therefore, layering of figures is a common feature that is present in advertising slogans.

Although there was linguistic diversity in advertisements that existed 100 years ago, they did not include the whole range of figures such as puns that were found in later advertisements (Myers 1994). Advertisements towards the end of the $19^{\text {th }}$ century employed 'rhymes, repetition, parallelism, scientific and literary language' with the aim of establishing brands. From the 1920s, advertisements linked brands with social meanings. This was achieved through the use of 'narrative formats, associative language, and metaphorical substitution of one thing for another' (Myers, 1994, p. 27). In the later period, specifically from the 1960s, advertisements were targeted at the disenchanted consumer saturated with the barrage of advertisements surrounding them. The advertisers used all sorts of strategies to attract and maintain the consumers' attention towards their products and services.

\section{Rhetorical Strategies in Advertising}

Over the years, advertisers have used various strategies to persuade consumers. Deixis in discourse possesses the feature of 'pointing' or 'showing', directing a particular speech towards the notion of time and space. Deictic words, however, rely on the 'situation' or 'context of utterance' (Goddard, 1998, p. 106, 125; Leech, 1966, p. 156; Wales, 1990, p. 99). The reader has some prior knowledge of what the deictic words refer to. Deictic words such as this, those, it and there can be used for cross-referencing to refer to the linguistic context in advertisements. They can also be used to refer to the non-linguistic context in advertisements which are accompanied by visuals (Leech, 1966).

Particularity of reference is a feature of proper names and grammatical items. In advertising, the brand name is considered a proper name used to refer to a product or service. The grammatical items mentioned refer to personal pronouns, articles, demonstratives and adverbs of place and time, all of which 'point to, some entity, entities, place, time etc., given or understood from their context' (Leech, 1966, p. 156). Products advertised are also personified by labelling them with personal names or brand names, for example, Mr. Muscle for a bottle of oven-cleaner and Mister Print for a print and design company respectively. Consumer-friendly corporate bodies use personal pronouns such as we in their advertising to lend a friendly and personal image of themselves to the consumer (Wales, 1996).

The definite article is used to demonstrate uniqueness of a referent. Appositional constructions in advertising most often employ the definite article together with the brand name as the first element such as in, Wisdom. The 'correctshaped' toothbrush (Leech, 1956, p. 157). In advertising, there are also words that express uniqueness explicitly such as the adjective, unique itself and only, in for instance, 'the unique prescription for colds and flu' and 'the only chocolate flavoured cereal' respectively. Superlative adjectives also belong in this category. These words that express uniqueness directly are deictic in nature as they always follow the definite article the in the noun group although there are exceptions like, 'a best man' or 'an only child' (Leech, 1966, p.158).

Kenneth Burke describes the influence of symbols in communication. Persuasion is 'the use of symbols, by one symbol-using entity to induce action in another' (1969, p. 46). His comprehensive Theory of Dramatism focuses on the use of symbols in communication. The dramatistic concept helps us explain and rationalize situations. The situations depend a great deal on the symbols used by people belonging to any particular social group (Gusfield, 1989). Hence, we can say words influence both persuader and audience to identify with each other. Three ways in which this identification is accomplished are through symbol use, naming and framing. The symbols used by persuaders and the ways these symbols are used will govern their success at persuading an audience.

There are three main symbols that persuaders use to add forcefulness to their message. One of these symbols is the negative which linguistically means saying that an object or concept/ idea is not something else. The negative is thus intrinsic in our use of symbols (Borchers, 2002). The concept of negativity is prevalent in figures of speech such as the antithesis, metaphor and irony. The negative is also a strategy used in advertising as in the Federal Express (Fed Ex) slogan, When there's no tomorrow and the Listerine mouthwash slogan, The taste you hate twice a day. Burke fully supports the use of the negative 'in an advertising world that is so strong on the glorification of the positive' (Burke, 1966, p. 12).

The second feature of language connected to symbols is hierarchy or social structure. Man is spurred on by the force of hierarchy which 'sets up the characteristic social elements' that humans deal with. In other words, we are 'moved by a sense of order' (Burke, 1966, p. 15). There are higher and lower, right and wrong, better and worse, upper and lower (Gusfield, 1989, p. 38). Just as society is hierarchical, so is language. When we use language to distinguish between people, objects or places, we unconsciously form structures in which one word occupies a higher position than another. Symbol use makes us strive to go up the ladder in order to achieve our goals and ambitions in life. This hierarchical 
aspect of language use leads to competition and persuaders exploiting our desire for success by advertising their products or services (Borchers, 2002). This is evident in slogans such as, Better than anything (Haagan-Daz) and Avis Rental Car's We're number two. We try harder.

Burke says that we are 'rotten with perfection' (Burke, 1966, p. 16). Perfection, the third characteristic of the symbol use, is fundamental to the identity of language as motive. The urge to use the correct name to refer to something or to speak a language in its characteristic ways is essentially being a perfectionist. Symbol use results in us constantly being in pursuit of the best. Advertising makes use of appeals in the superlative such as 'best', 'quickest' and 'tastiest' (Borchers, 2002, p. 171-172). Examples are Gillette's slogan, The best a man can get and Honda's You meet the nicest people on a Honda.

Burke refers to the word 'motive' as how we consider a particular situation, i.e. our way of framing it will affect the way we view people and the world in general. In a nutshell, persuaders can use language to shape the way the audience views the world. This concept of framing is also prevalent in advertising slogans. For instance, the slogan, Expanding possibilities places the company, Hewlett-Packard, as the agency 'for an individual's or an organisation's computing success'. Similarly, Where do you want to go today?, Microsoft's slogan, also suggests 'that its products can help individuals or organizations achieve their goals' (Borchers, 2002, p. 182).

Today we are exposed to more information about the persuader (Borchers, 2002) as persuasion is brought right to the 'intimate environment' of our living rooms through the medium of radio, and particularly, television (Jamieson, 1988, p. 55-56). Thus, electronic eloquence came about with the introduction of television which changed the once 'impassioned appeals' to 'a cooler, more conversational art' (Jamieson, 1988, p. 44). Myers (1994) stresses that even since the start of the copywriting profession, copywriters had always been trained to ensure that advertising sounded like conversation and not like a sales pitch or a political speech although a bit of sales pitch was essential. Advertisements rely heavily on the use of everyday talk especially when the product tends to be associated with taboos or when the audience has established suspicions of the product.

Advertising slogans such as Clairol's, Does she or doesn't she? and Wendy's, Where's the beef? also became colloquial when they were used in cliff-hanging plots of audio-visual advertisements (Myers, 1994). Even with a host of new media around us today, advertisements seem to employ features of spoken communication. For instance, advertisements via the electronic mail (e-mail) and mobile phone text messages are written but they consist of many features of oral conversation (Cook, 2001). Advertising discourse, therefore, communicates to us through the use of real world or everyday life situations (Williamson, 1978; Myers, 1994). Conversationalisation, to an extent, can be attributed to the spread of consumerism. As a result, both public and private sectors are changing their practices and cultural orientation towards this direction (Fairclough, 1995).

There is a progression in advertising history which accumulates the appeals used by advertisers with the earlier periods still retained (Myers, 1994). Research on slogans over the years has not been documented in detail. Scholars have made impressionistic observations on the historical development of slogans in advertising but this area has not been tested. Therefore this study examines the trends of the use of rhetorical figures and persuasive strategies in the advertising slogans selected from the late 1800 s through to the $21^{\text {st }}$ century.

\section{Methods Used}

\subsection{Research Design and Selection}

This study seeks to analyse advertising slogans from at least 100 years ago. The study covers slogans which were created in the late nineteenth century, those which were created in all decades of the twentieth century to slogans which were created from the year 2000. A total of 500 slogans were selected from both product and service sectors of multinational companies. Overall, there are eight categories the slogans fall into. They are food and drink, tobacco, automobile, airline, photography, electronics, computing and fashion. Various categories were selected to ensure that the rhetorical patterns, if any, that emerged from the study would be consistent. The varied selection would also eliminate the possibility of some product or service categories using more rhetorical figures in their advertising than others 'because of some intrinsic characteristic of the product' or service (Phillips and McQuarrie, 2002, p. 10). Another important criterion for the selection of these slogans was that the products or services concerned or the companies involved were internationally popular or well known. This was determined from the profiles of the particular companies found in encyclopedias as well as from the company websites. The products or services were also considered if the researcher, being from Asia where these products or services did not originate, was familiar with them in her own country or had, at 
the very least, heard of the brand name or company. It is important that '....a rhetorical figure draws on a specific body of preexisting sociocultural knowledge' (McQuarrie and Mick 1996, p. 433).

\subsection{Selection of Companies/ Organisations}

The companies were selected based mainly on the availability of not only the advertising slogans but also the corresponding years or decades in which they were created. The 13 companies selected were British American Tobacco Plc., The Coca-Cola Company, Continental Airlines, Daimler Chrysler, Dr Pepper Snapple Group, Eastman Kodak Company, Ford Motor Company, The General Electric Company, Guinness \& Co., H.J. Heinz Company, IBM Corporation, Maidenform Inc., PepsiCo, Inc.

\subsection{Data Collection}

A pilot study was conducted to determine the presence of rhetorical figures and persuasive strategies in advertising slogans. For the purpose of gathering data for the pilot study, a small sample of 24 advertising slogans was selected. A total of 500 advertising slogans were eventually gathered for the main study. This number included the slogans used for the pilot study. The advertising slogans for both the pilot and main study were obtained from various sources such as encyclopedias, company websites, news websites and registered online advertising sources.

\subsection{Data Analysis}

The data for the main study was analysed quantitatively to determine the mean and/or percentages of rhetorical figures and persuasive strategies present in the advertising slogans studied. It was also used in order to analyse any trends or patterns that emerged. The slogans of each company were first arranged in chronological order then grouped into decades starting from the late 1800s depending on the individual companies. Then the findings of the pilot study in combination with McQuarrie and Mick's taxonomy (1996) were used to identify rhetorical figures found in each of the slogans. If a figure was identified, it was categorised and coded as a scheme or trope accordingly. The data was also scrutinised for the presence of communicative and stylistic strategies obtained from the results of the pilot study which were also coded. Each slogan was also examined to see if there was a layering of figures. The layering of rhetorical figures in advertising slogans is determined by calculating the total number of rhetorical figures per decade and dividing this by the total number of slogans per decade to get the mean per decade.

Mean and/or percentages were used to determine the trends found in the use of rhetorical figures and persuasive strategies in the advertising slogans studied over time, specifically, by decades. The trends according to the various categories and incidences were portrayed graphically. To support the analysis, the background or general situation of the company or organisation was examined, particularly around the time the slogan was created. ${ }^{1}$

\section{Findings and Discussion}

The qualitative analysis has revealed that both schemes and tropes are present in advertising slogans. However, there appears to be more schemes in slogans of the earlier decades (up to the 1950s) than in the later ones (after the 1950s). In slogans of the later decades, more tropes than schemes are used. The schemes that are used the most in the slogans analysed are parison, assonance and chime. The tropes that occur the most are metonymy, ellipsis, pun and metaphor.

Communicative strategies were found to be used in the slogans analysed. Burke's Theory of Dramatism is extensively applied in the slogans. Either the use of Burke's symbols or his concept of framing or a combination of both can be found in nearly every slogan analysed. The analysis also reveals the use of several stylistic strategies. Deixis and personalisation were used extensively in the slogans. In particular, personal pronouns were used to foster a link between the persuader and the consumer. Deictic words were found to serve the function of pointing to a particular context. Absolute uniqueness was also reflected in various ways in the slogans. Slogans in the late 1990 s and the $21^{\text {st }}$ century took on a more imaginative approach. Fragments and other linguistic violations of a grammatical and orthographic nature were found to occur in these slogans as they became shorter in length.

\footnotetext{
${ }^{1}$ The year or decade each slogan was created is indicated in brackets beside the slogan.
} 
The analysis also revealed the use of idioms as the base of a few slogans. Several slogans also included the brand name but many did not. There were also no outright cases of slogans being conversational although a few had slight hints of a conversational tone. Sexual innuendoes were present in a very small percentage of the slogans.

Figure 1 demonstrates the trend of the use of communicative and stylistic strategies in the advertising slogans analysed between 1886 and 2008. As can be seen, deixis and personalisation occurs in all the decades analysed. It had a high occurrence in the decade of 1910 but started to gradually decline until the 1950s. However, it began rising again in the 1960s right up till the 1980s when it reached its highest mean of just under 1.2. Its use then dropped in the 1990s and in the decade of 2000. Overall, the pattern is that of rises and falls throughout the decades with its lowest mean of about 0.5 in 1900-1909. A similar rise and fall pattern applies to the use of the brand name, Burke's symbols, deviant styles, idioms and linguistic violations. Lastly, the use of sexual innuendos as a strategy occurred only in the 1930s, 1940s, 1960s, 1970s and 1990s with a low mean of under 0.1. The findings also show a rise and fall pattern in the layering of schemes and tropes. In the last 40 years, the layering of schemes and tropes in advertising slogans shows a decrease. This is parallel to the finding that slogans are becoming shorter with the use of more tropes.

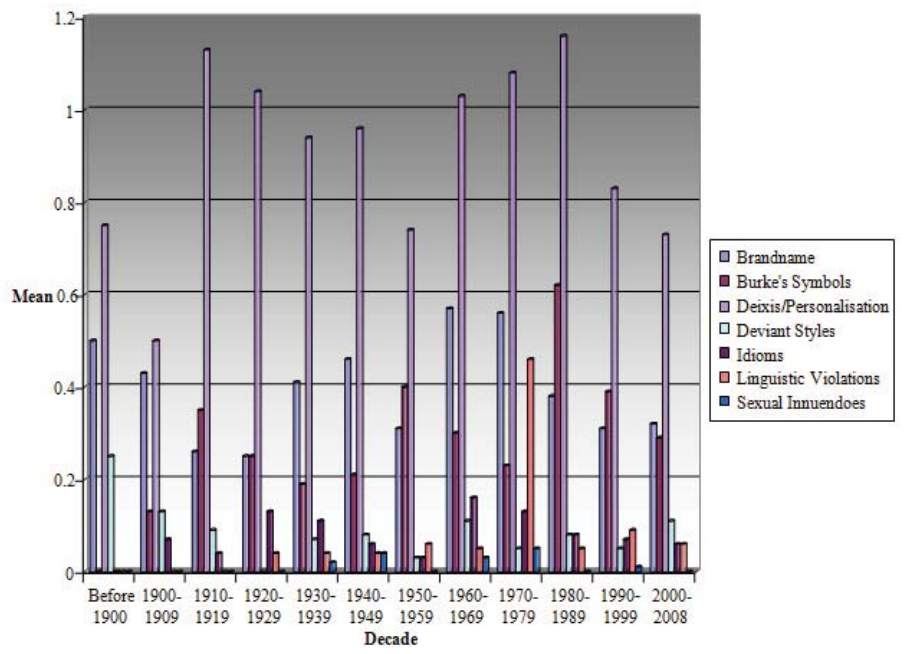

Fig. 1. Trend of Communication and Stylistic Strategies from 1886-2008

\subsection{The Different Periods of Advertising}

Through the analysis of advertising slogans carried out over more than ten decades, the study has unveiled significant trends. Myers' (1994) division of advertising is categorised into three periods right up till the early nineties. Myer's periods have been updated to include the first decade of the $21^{\text {st }}$ century as follows:

a. the 1890 s till 1919

b. the 1920 s till the 1950 s

c. the 1960 s till the $1980 \mathrm{~s}$

d. the 1990 s till 2010

a. The late $19^{\text {th }}$ century was the beginning of the advertising era as commodities and markets began to develop. It was also the period of the beginning of many existing brand names (Myers, 1994). The data show that organisations like The Coca-Cola Company used the brand name and stated the product benefits at the same time. Examples are the slogans, For headache and exhaustion, drink Coca-Cola (1900), Coca-Cola is a delightful, palatable, healthful beverage (1904) and Delicious Coca-Cola sustains, refreshes, invigorates (1907).

Persuasive devices and strategies were used to make the slogans catchy. This tallies with Myers's (1994) observation that the linguistic devices used during the late 1890s and early 1900s, included having a catchy rhyme or slogan and this was achieved through the use of schemes. Only linguistic violations were totally absent in slogans of the 1890s till 1919. Instead the message was delivered in a direct fashion without the use of complicated structures. In other words, although the advertising slogans of this period showed linguistic 
diversity, they lacked the rhetorical and stylistic sophistication found in the later slogans. Out of fifty-seven slogans of this period, there was only one instance of a pun.

The First World War which began in 1914 did not considerably weaken advertising whether it was in the U.S, England or Canada. Copywriters could directly relate sales appeals to the war. Business organisations gave their advertising slogans patriotic overtones, particularly for essential items such as household, personal care and food. Conservation themes, especially in food advertisements, were commonplace. Recommendations were made for the substitution of products in abundant supply for goods needed for the war. Advertising campaigns were tailored towards conveying patriotic messages as not only products but also ideas were sold (McDonough, 2002; Pope, 1980).

b. The second period, the 1920s till the 1950s, sought to develop an image for the consumption of goods and services. The advertising industry was 'just approaching maturity' and therefore 'stood ready with fresh patterns' (Fox, 1984, p. 78). There was a big shift from focusing on production to focusing on the association of meanings with consumption (Myers, 1994). Advertisements depicted the lifestyle associated with using or not using the product. Examples of advertising slogans during this period are Daimler Chrysler's Your next car (1950s) and British American Tobacco's Modern design makes the difference (1939). There was a surge in persuasive devices and strategies such as the pun, metonymy and idioms which were used considerably during this period. In other words, advertisements of this period were 'selling a better life' as illustrated:

The appeal was not BUY OUR SOAP but rather BUY a better life by buying OUR SOAP (Myers, 1994, p. 24).

British American Tobacco, for instance, persuades consumers that by smoking Lucky Strike cigarettes, they would lead a happy-go-lucky life. Hence, they used the slogan, Be happy-go-Lucky! (1950). On the other hand, it was not only the 'pleasures of leisure time' that the advertisements focused on but also the 'fear of social comparisons', 'creating a new problem', 'broadening the range of choices' and 'associating different meanings with different styles' all with the aim of boosting consumption (Myers, 1994, p. 23-24). Associating a particular meaning with a particular style was also used as a way of increasing consumption. The Coca-Cola Company is especially fond of using this method. They used slogans such as The sociable drink (1925) and Meet me at the soda fountain (1930) to associate the drink with social life and friendship in order to attract young consumers.

Myers (1994) did not take into account the fact that this period covered the Great Depression and World War II. The Great Depression lasted from 1929-1933 and the Second World War took place from 1939-1945. During World War II in 1941, advertising took on war-related themes. Hence, the H.J. Heinz Company, for instance, played its part in the war effort with the slogans, Pickles to pursuit planes and Beans to bombers (McDonough, 2002).

The growth of the new medium of television in the 1950s had a great influence on advertising. Jamieson's (1988) electronic eloquence can be applied here as persuasive messages are brought to the intimate environment of people's living rooms in a more conversational way. The slogans of the 1950s such as Dr Pepper's The friendly pepper-upper and Eastman Kodak's Open me first illustrate a conversational style which would engage the audience with the advertisements and their respective messages. In Dr Pepper's The friendly pepper-upper, the neologism, pepper-upper, gives the slogan an informal touch and this is reinforced by the adjective friendly. In Eastman Kodak's Open me first, the imperative, open, used with a personal pronoun, me, in the context of opening Christmas presents, gives this slogan not only a personal but also a conversational ring to it.

Television reinforced the message of slogans through repetition which became very effective (McDonough, 2002). On the other hand, the 1950s advertisements were criticized as being bland and unimaginative throughout the decade (McDonough, 2002). What this meant was that advertising began to reach saturation point during this period. Consumers were bombarded with messages from all corners, especially with the advent of television.

Consumers may have been familiar with the numerous slogans that came their way at that time but according to critics, what they needed was something different, something more creative. Examples of slogans of the 1950s from the data are: Coca-Cola's Help yourself to refreshment (1950), Ford Motor Company's Speak first with Ford (1950s), The General Electric Company's Progress is our most important product (1950s), Guinness \& Co.'s Christmas time is Guinness time, IBM Corporation's A tool for modern times and PepsiCo Inc.'s Refreshing without filling (1954). There was certainly not much creativity shown in such advertising slogans 
even if they attracted consumers through repetition. Therefore, with conflicting views, the advertisements of the 1950s paved the way towards a new period.

c. The period beginning from the 1960s addressed the 'jaded consumer saturated with ads' (Myers, 1994, p. 28). A lot of famous advertisements of this period were 'ads about ads' such as the Avis slogan, We're only number 2. We try harder. (Myers, 1994, p. 25). Advertisers of this period addressed the jaded consumer 'with ironies, parodies, ads on ads, puns, and juxtaposition of competing discourses, in the text and the images' (Myers, 1994, p. 28). Advertisements during this period startled people with unconventional slogans and headlines such as Lemon for the Volkswagen car where the noun was 'colloquially used for defective cars'. Although irony is rarely used in advertising as it is 'potentially destructive of the whole shared enterprise', it was used in this Lemon campaign and in many other advertisements during the 1970s. 'Ironic advertising' worked here as it fitted in with 'the excesses of other advertisers' of this period (Myers, 1994, p. 25).

The analysis shows the use of puns, idioms and humour in the advertising slogans of the 1960s. Examples are It's opening time for canned Guinness (1960), Daimler Chrysler's Let yourself go (1966) and Lucky Strike separates the men from the boys...but not from the girls (early 1960s) respectively. Due to the evolving nature of commodities and the different personalities of advertising agents, copywriters in the 1970s somewhat ridiculed the humour and language play that was used in the 1960s (Myers, 1994). The analysis of this study, however, illustrates that the slogans of the 1970s also used puns such as the Guinness slogan, An Arthur Guinness production (1979). These slogans also show creativity and humour such as Ford's The score for '76: Mustang 11. Boredom 0. Another creative and rather unconventional one is Pepsi's 1973 slogan, targeted towards young people:

\section{Lipsmackin'thirstquenchin'acetastin'motivatin'goodbuzzin'cooltalkin'highwalkin'fastlivin'evergivin'coolfizzin' Pepsi}

This slogan is unconventional as we do not usually come across a combination of nine adjectival compounds and an adjective meant to form a long, single adjective with apostrophes denoting contractions to replace commas. In addition, a few adjectival compounds like lipsmackin' are common but others like goodbuzzin' are not.

The slogans of the 1980s also show the use of idioms and humour such as in Dr Pepper's Just what the Dr ordered (1987). Therefore, in general, the data and analysis do illustrate the use of a few unconventional slogans during the period of the 1960s-1980s. What types of slogans abound in the 1990s and in the beginning of the new century?

d. The 1990s till the present falls in the period of the media age. We live in a mediated, social and technological era of contemporary society. Is it surprising then that 'In today's world of mediated persuasion, much is left unsaid'? (Borchers, 2002, p. 20). Accordingly, today's advertisements do not make claims about the product or service as the audience is already well aware of the proposition that will be put forward by the advertiser (Slayden, 1999. In Borchers, 2002).

It is taken for granted that advertisers today are not genuine in their act of persuading and to solve this problem, the advertiser should see the consumer as 'an active and disenchanted interpreter' (Myers, 1994, p. 26). Consumers, in turn, tend to follow the crowd in that we feel a lot safer knowing that other people are doing the same thing; a natural inclination. Advertising today is competitive as advertisers have to compete for attention in the midst of many products that make similar claims. Advertisers may not seem a trustworthy lot but we still fall for their rhetorical strategies which includes stereotyped lifestyles depicted in advertisements (Wilmshurst, 1985). On the other hand, after experiencing decades of advertising, the consumer has become more skilful in decoding advertisements. Hence advertisers become more daring as they are faced with the challenge of coming up with novel ways to attract and persuade the consumer.

The analysis of this study shows that advertising slogans of this period have the tendency to be a lot shorter than their predecessors. One or two-word phrases and fragments are being increasingly used in today's slogans. This conforms to deviant styles which, in this case, is the short, clipped masculine style. Accordingly, the shorter the slogans, the more the tropes and the fewer the schemes become. This corresponds to the results of the quantitative analysis that slogans from the 1990s to the present contain more tropes than schemes. Apart from fragments, advertisers are also resorting to linguistic violations such as being ungrammatical, using unorthodox spelling, vocabulary and lexis to set their slogans apart from the others.

Advertisers are also using framing by acting as agents in helping shape the consumer's future.

Examples of slogans having these features are Pepsi's More happy (2007), Maidenform's They crave passion 
(1990s), IBM's Are you ready for e-business? (1998), Guinness's Brilliant! (2005), Daimler Chrysler's Hi (1994) and Dodge. Different. (2000), Dr Pepper's Be you (after 2001) and Coca-Cola's One and only (2003).

\subsection{The Rise and Fall Pattern}

The quantitative analysis shows a rise and fall pattern throughout the decades of both rhetorical figures and communicative and stylistic strategies used in advertising slogans. The pattern was also present in the layering of the rhetorical figures throughout the decades.

In relation to advertising, the findings of this study clearly show the presence of the cyclical pattern that involves the selection of certain rhetorical figures and persuasive strategies in a particular period but not in others. This rise and fall pattern can be likened to the effect of a pendulum which swings back and forth without stopping as language is dynamic and moves all the time. The oscillating pattern in advertising occurs where one generation of advertisers employ a set of figures and strategies and the next generation would discard them and reinvent the wheel. The results of the analysis of this study are testimony to this. This trend does not only occur with a change of generation but also with the introduction of new media and the expectations of consumers. Advertising also has to embrace 'currents of social discontent' which may have an adverse effect on the 'industry's freedom of action' and eventually on the basic economic principles (Vestergaard and Schroder, 1985, p. 121). In fact, advertising is constantly striving to keep its grip on the future to ensure production and sales run smoothly.

Therefore, we have seen the presence of the oscillating pattern in advertising based on this study. For the first to the last decade of the analysis, the researcher has devised a cyclical continuum that begins from the late nineteenth century till the beginning of the twenty-first century. Figure 2 illustrates the characteristics of advertising slogans from one end of the spectrum to another. On the one extreme are the characteristics of the early slogans and on the other are the characteristics of the current slogans. The early slogans are categorised as straightforward and did not mislead the consumer as they aimed to provide information about product benefits. They also consisted of more schemes than tropes. The slogans also conformed to linguistic conventions. On the other extreme, the slogans puzzled the consumer, used more tropes than schemes and did not conform to linguistic rules. In between these two extremes, the characteristics could move back and forth. They could be found in one decade but not in another following a cyclical pattern.

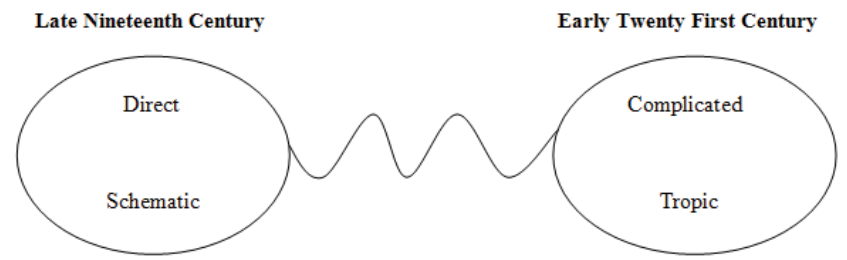

Fig. 2. A Cyclical Continuum of the Characteristics of Advertising Slogans

\section{Conclusion}

As we are now well into the twenty-first century, with more exposure to the media creating greater competition among advertisers, impressionistic observations alone are insufficient. More research needs to be carried out in this area of advertising. Copywriters demonstrate an innate ability and innate sensitivity in forming a pattern and then reforming it, that is, they are spontaneously creating and recreating. We do not usually notice specific patterns in advertising unless they are formally analysed. This study has therefore identified patterns inherent in advertising slogans.

\section{References}

Borchers, T.A. (2002). Persuasion in the media age. New York: McGraw-Hill.

Burke, K. (1966). Language as symbolic action: Essays on life, literature, and method. Berkeley: University of California Press.

Burke, K. (1969). A rhetoric of motives. Berkeley: University of California Press.

Cockcroft R. and Cockcroft, S.M. (1992). Persuading people. London: Macmillan Press.

Cook, G. (2001). The discourse of advertising. $2^{\text {nd }}$ ed. London: Routledge.

Corbett, E.P.J., and Connors, R.J. (1999). Classical rhetoric for the modern student. 3rd ed. Oxford: Oxford University Press.

Fairclough, N. (1995) Critical Discourse Analysis. Essex: Longman. 
Fox, S. (1984). The mirror makers. New York: Vintage Books.

Goddard, A. (1998). $2^{\text {nd }}$ ed. The language of advertising. London: Routledge.

Gusfield, J.R. (1989). Kenneth Burke. On symbols and society. Chicago: The University of Chicago Press.

Jamieson, K.H. (1988). Eloquence in an electronic age. Oxford: Oxford University Press.

Leech, G.N. (1966). English in advertising. Essex: Longman.

McDonough, J. (2002). Encyclopedia of advertising. Vols. 1, 2 \& 3. Chicago: Fitzroy Dearborn.

McQuarrie, E.F. and Mick, D.G. (1996). Figures of rhetoric in advertising language. Journal of Consumer Research, 22, 424-438.

Mothersbaugh, D.L., Huhmann, B.A., and Franke, G.R. (2002). Combinatory and separative effects of rhetorical figures on consumers' effort and focus in ad processing. Journal of Consumer Research, 28(4), 589-602.

Myers, G. (1994). Words in ads. London: Edward Arnold.

Philips, B.J. and McQuarrie, E.F. (2002). The development, change and transformation of rhetorical style in magazine advertisements 1954-1999. Journal of Advertising, 31(4), 1-13.

Pope, D. (1980). The advertising industry and World War 1. The Public Historian, 2(3), 4-25.

Slayden, D. (1999). Vicarious realities: internet discourses and narratives of the future. In: Slayden, D. and Whillock, R.K. (Eds.). Soundbite culture: the death of discourse in a wired world. In: Borchers, T. Persuasion in the media age. New York: McGraw Hill. Vestergaard, T. and Schroder, K. (1985). The language of advertising. Oxford: Basil Blackwell.

Wales, K. (1990). A dictionary of stylistics. $2^{\text {nd }}$ ed. Essex: Pearson Education Limited.

Wales, K. (1996). Personal pronouns in present-day English. Cambridge: Cambridge University Press.

Wilmshurst, J. (1985). The fundamentals of advertising. Oxford: Butterworth-Heinemann.

Williamson, J.W. (1978) Decoding advertisements. Ideology and meaning in advertising. London: Marion Boyars. 